\title{
Intercultural Communication in Modern Linguistic Space
}

\author{
Nadezhda Nikolova
}

Institute for Bulgarian Language „Prof. L. Andreychin“, Bulgarian Academy of Sciences, Bulgaria

\section{Междукултурната комуникация в съвременното лингвокултурно пространство

\author{
Надежда Николова
}

Институт за български език „Проф. Л. Андрейчин“, Българска академия на науките, България

\section{Author Note}

Nadezhda Nikolova

https://orcid.org/0000-0002-1076-7964

The author has no conflict of interest to disclose.

Correspondence concerning this article should be addressed to Nadezhda Nikolova, Sofia 1113, 52 „Shipchenski Prohod“ B1., Block 17. Institute for Bulgarian Language „Prof. L. Andreychin“, Bulgarian Academy of Sciences, Bulgaria, Email: nvnikolova@abv.bg

\section{Бележки за автора}

Надежда Николова

https://orcid.org/0000-0002-1076-7964

Няма конфликт на интереси.

Кореспонденцията, свързана с тази статия, да бъде адресирана до Надежда Николова, София 1113, бул. „Шипченски проход“ 52, блок 17, Институт за български език „Проф. Л. Андрейчин“, БАН, България, Email: nvnikolova@abv.bg 


\begin{abstract}
Intercultural contacts are very dynamic in the modern world. Intercultural interaction at personal, institutional, and international levels, due to globalization, demographic changes, information technologies development, etc., is intense. The expansion of international relations these days requires developing dialogic skills between various developed cultures, which requires clarification of problems related to intercultural communication. The article analyzes the concepts of intercultural communication in modern society. It also highlights some characteristics, trends, and development in the linguistic space.
\end{abstract}

Keywords: intercultural communication, culture, international relations, linguistic and cultural contacts, linguistic culture

\title{
Резюме
}

Динамични са междукултурните контакти в съвременния свят. Интензивно е междукултурното взаимодействие в лично, институциално и междудържавно ниво, дължащо се на глобализацията, демографските промени, развитието на информационните технологии и др. Разрастването на международните отношения в нашата съвременност предхождат развитието на умения за диалог между различни развити култури, което изисква изясняване на проблемите, свързани с междукултурната комуникация. В статията се анализират концепциите за междукултурна комуникация в съвременното общество. Посочват се характерните особености, тенденциите и развитието й в лингвокултурното пространство.

Ключови думи: междукултурна комуникация, култура, международни отношения, езикови и културни контакти, лингвокултурология.

\author{
ARTICLE INFO: \\ Original Article \\ Received: 26, 02.2021 \\ Revised: 20, 03.2021 \\ Accepted: 25, 03.2021
}




\section{Междукултурната комуникация в съвременното лингвокултурно пространство}

Процесьт на глобализацияводи до интензивно разширяване на междукултурните контакти, нараства взаимното влияние на различнистрани, народи и техните култури. Голямо влияние има междукултурната комуникация, която се извършва чрез културния обмен и преките контакти между държавни институции, социални групи, движения чрез научно сътрудничество, туризма, търговията и др.

Високоскоростните транспортни средства, съвременните средства за комуникация, глобалната информационна мрежа интернет сближиха хората, направиха света толкова близък, казва А. Садохин, че взаимодействието на държави, народи и култури стана неизбежно и постоянно (Sadohin, 2019, p.7).

През последните десетилетия наред с този многократно споменаван факт, неизбежно следствие от дълбоките световни политически, икономически и технологични промени, се отбелязва и разочарованието от настьпилото „разбиране между народите“. В историята на глобализацията се показва ясно, че сближаването на културите, породено от заличаването на факторите „време и пространство“, не протича така безпроблемно. В голяма степен според Й. Рот и Й. Попова „много от съвременните проблеми и конфликти се дължат на „културните сблъсаци“, които възникват в резултат от близкото съжителство на хора от различни представи, ценности и норми“ (Rot \& Popova, 2005, p. 4). Известно е, че контакти между представители на различни култури е имало винаги, отличителна особеност на нашето съвремие е тяхната динамика, задълбочеността им, както и проникването им в нови сфери на професионалното и лично ежедневие, останали незасегнати досега от културното многообразие. В този смисъл съсредоточаването на вниманието върху междукултурната комуникация, като поле за изследвания в съвременния свят, става все по-актуално.

Темата за междукултурната комуникация става актуална през 60-те години наминалия век преди всичко във врьзка с работата на Едуард Хол (1954) и не само не губи своята актуалност, но става все по-привлекателна за представителите на различни научни области. Към нея проявяват интерес философи, социолози, лингвисти, психолози, педагози, културолози, антрополози и редица други специалисти. Голяма част от тях се опитват да обяснят механизма през призмата на своята предметна ориентация и да дадат предписания за повишаване на ефективността на комуникативния процес. Други анализират процеса тясно предметно и извеждат 
закономерности. Трети използват мултидисциплинарни подходи, за да могат да намерят решения на проблемите, които се проявяват в хода на изследването на този сложен феномен.

Основните теми на специалните изследвания на теорията и практиката на междукултурната комуникация са съсредоточени върху проблемите на успеха/неуспеха на комуникацията между представители на различните етнически (национални) лингвокултурни общности, идентифициране на причините за неуспехите, идентифициране на различията в комуникативното поведение на говорещите различни езици и култури, както и различията в организацията на езиковите и нелингвистичните кодекси за качеството на междукултурната комуникация.

Терминът „интеркултурна комуникация“ е въведен от американския антрополог Едуард Хол, съвместно с лингвиста Тейгър още през 1954 г. (Trager \& Hall, 1954). Хол подробно анализира взаимоотношението култура и комуникация, аргументирано обосновава важността на междукултурния анализ, а така също разкрива възприемането на пространство и време на представителите на различни култури.

Българската изследователка И. Чонгарова определя интеркултурната комуникация като „общуване на представители на различни лингвокултурни съобщества. Тя е междуличностна комуникация, която се характеризира с определени сходства и различия на участниците в комуникацията с оглед техния език, начин на възприемане на действителността, ценностната система и поведение (както речево, така и неречево)“(Chongarova, 2002, p. 22).

Междукултурната комуникация, според други автори, трябва да се разглежда като съвкупност отразлични форми, взаимоотношения и комуникация между индивиди и групи, принадлежащи към различни култури (Golovleva, 2008, p. 25).

Междукултурната комуникация е комуникационният процес (вербален и несловесен) на хора (групи от хора), които принадлежат към различни национални лингвокултурни общности, по правило използват различни етнически езици, чувстват лингвокултурното „отчуждение“ на своя комуникационен партньор, имат различна комуникативна компетентност причиняват комуникационни неуспехи или културен шок в комуникацията. Интеркултурната комуникация се характеризира с факта, че нейните участници в случаите на пряк контакт използват средства от езиков код с културно специфични значения, както и комуникационни стратегии и тактики, които се 
различават от тези, които използват в случаи на взаимодействие в рамките на една и съща култура.

По този начин спецификата на междукултурната комуникация като посока на лингвистичните изследвания се крие в нейния интердисциплинарен характер, тясно свързани с проблемите, предимно комуникативна лингвистика, лингвокултурология, социолингвистика и етнолингвистика. Темата на изследването на теорията за междукултурната комуникация се формира на основата на комуникативните, езикопрагматични основи на взаимодействието на носителите на различни етнически култури със задължителното идентифициране на различията в техните психосоциологически принципи, които се проявяват в използването на културно-специфични значения.

Интересът към културната лингвистика и нейното развитие са свързани със значителни промени в научната парадигма, настьпила в началото на двадесети век. Имат се предвид нови идеи и подходи към изучаването на езика: антропоцентризъмът, включващ систематичното владеене на езика, неговите единици, текст и дискурс през призмата на „човешкия фактор“; когнитивизъм (езикът е резултат от когнитивната дейност, начина на организиране и съхранение на човешкото познание за света, пространството на мисълта и духа); езикови културни изследвания - тясно обвързване на езика и културата на народа, разбиране за развитието на езика в резултат на човешката творческа дейност (Varbanova-Dencheva, 2006; Peicheva, 2014).

Културата зависиот влиянието на езика. В някои култури интегралните лингвокултурни системи се създават с инвариантен (традиционно запазен) център и променлива периферия (променлива във времето под влияние предимно на

екстралингвистични причини). Лингвокултурните системи представляват лингвокултурни ситуации, представляващи динамичен и вълнообразен процес на взаимодействие между езици и култури в исторически установени културни региони и социални сфери.

Лингвокултурологията и етнопсихолингвистиката са тясно свързани науки. Всеки от тях фокусира онези характеристики на културата, които очевидно я свързват с езика. Например, лингвокултурологът В. Маслова говори за културата като набор от „правила на играта“ на колективното съществуване, набор от методи на социална практика на колектива, които хората са развили за социално значими практически и интелектуални действия (Maslova, 2001, p. 12). Езикът определя 
естеството на мисленето, начина на познаване на света, засяга ума и поведението на човека.

Отношението към езика като културно явление, описващо го от тази гледна точка, изисква внимание към характеристиките на националния манталитет и тяхното отразяване в речника, фразеологията, речевият етикет, концепциите и естеството на дискурсивната дейност на определена култура. Езикът е най-ценният източник на формиране и проявяване на манталитета на един народ, чрез който културата се запазва и предава на други поколения. Като обществено достояние, езикът се усвоява от всеки член на общността, което дава възможност да се оформят себе си, собствените гледни точки за света. В центъра на вниманието е лингвистичната личност в разнообразието на социално-психологическите роли, стратегии и тактики на комуникацията. Анализът на езиковата компетентност на индивида е съществен параметьр за описанието на културата.Най-ценният културен източник са фразеологични единици, метафори, символи и др. като носители на културата на представителите от народа.

Лингвокултурните изследвания са съвкупност от процеси и явления, където езикът е преводач на културна информация.Като носител на национален манталитет езикът на човек, участващ в съвместни действия с представители на други националности, погльща и дори „придава“ характеристики на друга култура, което сеотразява в същността на реалната комуникация, стратегията и тактиката на дискурсите. Идентификацията и самоидентификацията се базират на езика.

Междукултурното общуване предполага равнопоставено културно взаимодействие на представители на различни лингвокултурни общности, като се отчита тяхната оригиналност, което води до необходимостта от идентифициране на обикновените човешки същества въз основа на сравнение на чужди и лични култури и допринася за преодоляване на комуникативните пречки, счита А. Басова (Basova, 2003, р. 2). Взаимодействието на лингвистичните личности, обменът на информация, изборът на метод на влияние върху събеседника за осъществяване на съвместни дейности и пр. изискват адекватно разбиране, което може да бъде осигурено в контекста на общата социална предпоставка.

Междукултурната комуникация, която се разбира като комуникация между представители на различни лингвокултурни общности, обикновено се вписва в общия модел на комуникация. Но изучавайки характеристиките на междукултурната комуникация, трябва да видим национално определената специфичност на личността на 
лицата, която засяга характеристиките на кодирането на посланието, формата на контакта, възприемането на контекста. Тези компоненти са индивидуални и никога съвсем не съвпадат дори и с най-близките хора. В същото време е очевидно, че в случай на пълното отсъствие на „зона на пресичане“ не може да има истинска комуникация.

От гледна точка на културната лингвистика, Ф. Шарифия счита, че по време на междукултурната комуникация, събеседниците черпят културни концептуализации при конструиране, интерпретиране и договаряне на междукултурни взаимоотношения (Sharifia, 2013, p.68). Появата на глобализация и динамика на засилените контакти между хората от различни културни среди изискват нови понятия за „компетентност“, необходима за успешното междукултурно общуване. В новата дигитална ера комуникацията става все по-сложна, тъй като все по-често функционера интерфейс, в който езиците и културите се срещат и взаимодействат помежду си. В много контексти събеседниците в междукултурната комуникация са двуезични и многоезични и използват своя езиков репертоар като ресурс в сложни речеви ситуации (Sharifia, 2013, p. 74). С. Крамш отбелязва, че в такива контексти говорителите разкриват „символична компетентност“. Комуникаторите показват различна способност на общуване с времеви резонанси и различни езикови кодове (Kramsch, 2006, p. 249).

Новият етап на междукултурната комуникация, ярко илюстриран от интерградивните процеси в съвременна Западна Европа и създаването на ЕС, с установяване на европейско гражданство и всички произтичащи последствия, активно се обсъжда в политическите и обществени кръгове в страните.Проблемът за европейското гражданство придобива различни конотации и поражда нови препятствия при разбиране на понятието „гражданство“, по силата на това, че то различно се тълкува във Франция (политически), в Германия (културно), в Англия (административно-териториално).

Новите правни документи, приемани за определението на европейското гражданство, несъмнено трябва да интегрират всички тълкувания на „гражданството“, с цел осигуряване на адекватна междукултурна комуникация. Що се отнася до политическия и административно териториалния принцип, то те могат да бъдат реализирани, тъй като предполагат преди всичко активно формално начало, което не може да се каже за културния принцип.

От тази гледна точка най-напрегнатото звено се оказва актуализацията на културния принцип и във връзка с това, осмисляне на интеркултурната комуникация, 
която не може да бъде реализирана само с приемане на формалното начало на принципите на кооперацията. Действителната (естествена) интеграция изисква дълъг период на развитие на Европейския съюз, както по отношение интеграцията на вековните традиции на всяка страна, член на съюза, така и за придобиване на нови, общи традиции на съюза.

В Нова Европа възниква необходимост от умело съчетаване на особеностите на езиковата картина на света, от удачно комбиниране начините на живот, езиците. Проблемите, възникващи в процеса на междукултурната комуникация са свързани с различието на езиковата картина при жителите от страните на Европейския съюз.

Марк Феро предполага, че принадлежността към конкретна общност се създава не върху основа на знание на езика. Значимо е самото чувство за принадлежност към дадена общност (Fero \& Bermon, 2000).

Културният компонент в процеса на интеграцията представлява необходим минимум, способен да обедини и укрепи съвременното европейско мислене. Трябва да се уточни въпросът за възможността за разпространение на културните традиции в еднакъв режим на границата на столетията, когато се наблюдават миграционни процеси, при които става дума, не само за възприемането например, на културата на Франция от немците, но и за разбиране начина на живот, в който актуално и злободневно се открояват въпросите на бита и всекидневието, заострени от общите социални и политически процеси.

Междукултурната комуникация в България е актуална тема както за обществения дискурс, така и за научния свят. Факторите, които са предизвикали ангажиране с проблемите на интеркултурността в Европа, са налице и в България. Юлиана Рот посочва, че „присъединяването към големите международни структури на НАТО и Европейския съюз, засилването на миграцията от кризисните райони на Балканите, Близкия Изток и бившите съветски републики, както и повишената чувствителност към собствените „другокултурни“ общности от турци, помаци и роми, са явления, които по същество не се различават от сродните с тях в Германия, Франция, Холандия и пр“ (Rot \& Popova, 2005, p. 4).

Факт е, според А. Садохин, че процесът на глобализация, водещ до обединение на културите, поражда у някои народи желание за културно самоутвърждаване и предизвиква желание за запазване на собствените им културни ценности (Sadohin, 2019, p. 7). 
В последно време с повишаването на възможностите за виртуално общуване и пътувания контактите между българи и представители на други култури се увеличават.

Европейският парламент апелира към насърчаване на междукултурния и междурелигиозния диалог, както и на принципите и ценностите на Европейския съюз. Понастоящем технологичният напредък и бързото развитие на различни форми на международни контакти изпреварват развитието на комуникативни умения между представители на различни култури и исторически установени културни модели. Ето защо от средата на 70-те години. актуализирана стана темата за диалога и взаимното разбиране на културите, в която проблемът за специфичността, оригиналността и различията на културите на различните народи заема все по-голямо място (Sadohin, 2019 , p.7). Това може да стане чрез интернет и комуникационните технологии, които са ключови за улесняване на свободата на словото, плурализма, обмена на информация образованието, правата на човека и взаимодействието и приобщаването между културите и религиите. По този начин биха могли да се насьрчават толерантността и разбирателството за постигане на висока устойчивост на междучовешките и международните отношения.

Разширяването на Европейския съюз, повишаването на мобилността и необходимостта на гражданите да разберат бързо променящия се и силно взаимосвързан контекст - и да действат съответно - изправят България пред новите предизвикателства. Диалогьт между културите, езиковото разнообразие и общите преживявания на културното многоообразие и традиции са важен фактор за новаторските и творчески идеи на българина.

\section{Използвана литература}

Basova, A. (2003). Mezhkulyturnaya kommunikatsia v dialoge evropeyskih кulytur

[Intercultural Communication in the Dialogue of European Cultures]. https://elib.bsu.by/bitstream/123456789/147859/1.pdf

Chongarova, I. (2002). Interkulturna komunikatsiya. Aspekti na lingvokulturnata teoriya i praktika [Intercultural communication. Aspects of linguistic and cultural theory and practice]. Irida.

Ferro, M., Bermond D. (2000). European consciousness: myth or reality. Label France,40, $4-5$.

Golovleva, E.(2008). Osnovi mezhkulyturnoy kommunikatsii [Fundamentals of 
intercultural communication]. Moscow Phoenix Publishing House.

Kramsch, C. (2006). From communicative competence to symbolic competence, Modern Language Journal, 90(2), 249-252.

Maslova, V. (2001). Lingvokulyturologia [Linguoculturology]. Moscow Publishing Center Academy.

Peicheva, D. (2014). Metamorfozi i transformatsii v komunikatsionnoto prostranstvo i pismenata kultura[Metamorphoses and transformations in communication space and written culture]. In T. Shopova \& D. Peicheva (Eds.), Digitalna kultura i obshtestvo SWU Publishing House „N. Rilski“.

Rot, Y., Rot, K. (2007). Studii po interkulturna komunikatsiya [Studies in intercultural communication]. Academic Publishing House „Prof. M. Drinov“.

Rot, Y., Popova, Y. (2005). Rakovodstvo po interkulturna komunikatsiya. [A Guide to Intercultural Communication]. RU „A. Kunchev“.

Sadohin, A. (2019).Vvedenie v teoriyu mezhkulyturnoy kommunikatsii [Introduction to the theory of intercultural communication].Moscow Higher School Publishing House.

Trager, G., Hall, E. (1954). Culture and communication: A model and analysis. Explorations Studies in Culture and a Communication, 3, 137-149.

Sharifian, F. (2013). Cultural linguistics and intercultural communication. In F. Sharifi, and M. Jamarani (Eds.), Language and Intercultural Communication in the New Era.Taylor \& Francis.

Varbanova-Dencheva, K. (2006). Noviyat model napismenite komunikatsii v evropeyskoto Informatsionno prostranstvo opredelen ot poyavata na novite tehnologii [The new model of written communications in the European information space, defined by the emergence of new technologies]. Proceedings of the State Institute of Library Studies and Information Technologies (pp.95-102). Akademichno izdatelstvo Za bukvite - o pismenah. 